\title{
Agentes antimicrobianos mais utilizados na Odontologia: uma revisão de literatura
}

\author{
Antimicrobial agents most used in Dentistry: a literature review \\ Agentes antimicrobianos más utilizados en Odontología: revisión de la literatura
}

Recebido: 11/10/2021 | Revisado: 22/10/2021 | Aceito: 25/10/2021 | Publicado: 27/10/2021

Victor Felipe Farias do Prado

ORCID: https://orcid.org/0000-0002-9790-8001

Universidade de Pernambuco, Brasil

E-mail: victor.prado@upe.br

José Thiago Portela Gomes

ORCID: https://orcid.org/0000-0002-5930-7467

Universidade de Pernambuco, Brasil E-mail: thiago.portela@upe.br

Kamila Valleska da Costa Souza

ORCID: https://orcid.org/0000-0001-8772-5474

Universidade de Pernambuco, Brasil

E-mail: kamila.valleska@upe.br

Letícia Evêncio Sousa Luz

ORCID: https://orcid.org/0000-0002-7967-9997

Universidade de Pernambuco, Brasil

E-mail: leticia.luz@upe.br

Roberta Gomes Menezes de Lima

ORCID: https://orcid.org/0000-0002-6040-2429

Universidade de Pernambuco, Brasil

E-mail: robertamenezes.beta@gmail.com

Douglas Silva Martins

ORCID: https://orcid.org/0000-0003-2435-8093

Escola Superior de Saúde de Arcoverde, Brasil

E-mail: martinsdouglas03@gmail.com

Rodrigo Soares de Oliveira

ORCID: https://orcid.org/0000-0003-1002-2142

Universidade de Pernambuco, Brasil

E-mail: rodrigo.soaresoliveira@upe.br

Lindeberg Rocha Freitas

ORCID: https://orcid.org/0000-0003-3605-8282

Instituto Federal de Educação, Ciência e Tecnologia de Pernambuco, Brasil

E-mail: lindeberg@pesqueira.ifpe.edu.br

Francisco Braga da Paz Júnior

ORCID: https://orcid.org/0000-0003-1810-4011

Instituto Federal de Educação, Ciência e Tecnologia de Pernambuco, Brasil

E-mail: fraciscobraga@recife.ifpe.edu.br

Eliana Santos Lyra da Paz

ORCID: https://orcid.org/0000-0003-4486-142X

Universidade de Pernambuco, Brasil E-mail: eliana.lyra@upe.br

\section{Resumo}

Os antimicrobianos são drogas capazes de conter e reduzir a proliferação de microrganismos patogênicos, dentre eles, podemos destacar as bactérias e fungos. A sua prescrição é indispensável na prática odontológica e cabe, portanto, o conhecimento acerca das suas repercussões orais, posologias e contra indicações. Este trabalho tem como objetivo fazer uma revisão crítica da literatura mais recente acerca dos antimicrobianos mais empregados na prática odontológica. Para tanto, foi realizado o cruzamento dos descritores nas bases de dados no período entre 2010 e 2020 . Dentre as infecções de origem bacteriana, destaca-se algumas como: pulpite de origem bacteriana, abscessos odontogênicos, infecções periodontais e periapicais e endocardite bacteriana. Enquanto que nas infecções por fungos, a mais comum é a candidíase, que costuma ser tratada por duas classes de antifúngicos: os poliênicos e os azólicos.

Palavras-chave: Agentes antimicrobianos; Ação antimicrobiana; Odontologia.

\section{Abstract}

Antimicrobials are drugs capable of containing and reducing the proliferation of pathogenic microorganisms, among which we can highlight bacteria, fungi.Its prescription is indispensable in dental practice and, therefore, it is necessary to know about its oral repercussions, dosage and contraindications. This work aims to make a critical review of the most recent literature on the most used antimicrobials in dental practice. For this purpose, the descriptors were cross- 
referenced in databases in the period between 2010 and 2020 and among bacterial infections, the following stand out: pulpitis, odontogenic abscesses, periodontal and periapical changes and bacterial endocarditis. While in fungal infections, the most common is candidiasis, which is usually treated by two classes of antifungals: polyenic and azoles.

Keywords: Antimicrobials; Anti-infective agentes; Dentistry.

\section{Resumen}

Los antimicrobianos son fármacos capaces de neutralizar y reducir la proliferación de microorganismos patógenos, incluidos bacterias, hongos. Su prescripción es fundamental para la práctica odontológica, por lo que es adecuado el conocimiento de sus repercusiones orales, dosis y contraindicaciones. El objetivo de este trabajo es promover una revisión crítica de la literatura más reciente sobre los dos antimicrobianos más utilizados en la práctica odontológica. Para ello, se elaboraron o cruzaron dos descriptores en las bases de datos entre 2010 y 2020 . Entre las infecciones bacterianas destacan algunas como: púlpito de origen bacteriano, abscesos odontogénicos, infecciones periodontales y periapicales y endocarditis bacteriana. Si bien las infecciones por hongos son comunes, la cándida es más común, que generalmente se trata con dos clases de antifúngicos: polen y azol.

Palabras clave: Agentes antimicrobianos; Acción antimicrobian; Odontologia.

\section{Introdução}

O estudo dos microrganismos e seus fatores estabilizantes é objeto de estudo para incontáveis autores ao longo da construção da literatura acadêmica. Em especial na área médica, o entendimento do seu desenvolvimento e a compreensão dos seus mecanismos biológicos que estão presentes nas patologias é de vital importância para seu combate e controle. A cavidade oral é constituída por cerca de 1000 a 100000 microrganismos possuindo 300 espécies diferentes, como os patógenos e saprófitos, que estabelecem uma relação harmônica com o sistema imunológico do ser humano (Lira et al., 2001).

Contudo, alguns desses microrganismos possuem a capacidade de gerar um desequilíbrio homeostático uma vez que, interferem em vários processos metabólicos dos seres humanos. O metabolismo e o crescimento dessa microbiota são determinados por vários fatores, como dieta alimentar, microambiente, anatomia, presença de doenças e atividade do sistema imune (Samaranayake, 2012). Dessa forma, os antimicrobianos são substâncias escolhidas para conter e reduzir a proliferação desses microrganismos. Suas classificações variam de acordo com o seu espectro de ação, a atividade antibacteriana, o grupo químico e o mecanismo de ação (Neto et al., 2000).

A utilização controlada desses fármacos possui um protagonismo tanto na profilaxia quanto no combate a infecções oriundas de participação microbiológica, contudo, seu uso deve ser acompanhado e adequado as características individuais de cada paciente (Fuchs et al., 2017).

A microbiota humana contém um grupo colossal de microbiota como organismos procariontes (bactérias e Archaea) e eucariontes (fungos), que têm relação direta com a saúde e determinadas doenças humanas (Gonçalves, 2020).

A exemplo de doenças causadas pelos procariontes, temos a endocardite bacteriana que é provocada principalmente pela ação dos gêneros Streptococcus e Staphylococcus; ela é caracterizada pela inflamação do endocárdio, devido a intervenções odontológicas, das quais esses microrganismos seguem rumos na circulação e podem chegar às membranas e válvulas cardíacas, danificando-as (Cintra, et al., 2015).

Ainda em caráter bacteriológico, a migração das bactérias que estão num canal radicular inflamado para os tecidos periapicais e periodontais culminará num quadro clínico denominado abscesso e, portanto, cabe ao profissional lançar mão também de substâncias antibióticas a fim de obter uma resolutiva no processo patológico (Cintra, et al., 2015). Serão os antibióticos que assumirão o papel auxiliar na terapêutica das infecções, destruindo os microrganismos sensíveis ou impedindo sua proliferação (Andrade et al., 2014).

Enquanto nas infecções por fungos, a doença que se destaca é a candidíase. De forma geral, provocada principalmente pela Candida spp, ela afeta a cavidade oral, devido à pobre higiene oral, ao fumo e à dieta rica em carboidratos. Além disso, ela pode apresentar-se sob as formas: pseudomembranosa, eritematosa, hiperplástica e estomatite. Os antifúngicos atuarão nas 
micoses (doenças infecciosas ocasionadas pelos fungos patogênicos). Tais medicamentos podem exercer suas ações microbicida e microbiostática através de diferentes mecanismos atuantes nas estruturas dos fungos. A escolha ideal dos antifúngicos é orientada pelo quadro clínico geral do paciente, pelo tipo de micose e pela espécie fúngica que está ocasionando a patogenia (Millsop et al., 2016).

Dentre o vasto arcabouço medicamentoso disponível no mercado, o presente estudo possui como objetivo elencar os principais antimicrobianos utilizados na odontologia, bem como suas indicações, contraindicações e dosagem recomendada para cada um deles.

\section{Metodologia}

O presente estudo trata-se de uma revisão da literatura, desenvolvida por meio de fontes indexadas nas bases de dados do Scientific Eletronic Library Online (SCIELO), Literatura Latino Americana e do Caribe em Ciências da Saúde (LILACS) e Medical Literature Analysis and Retrival System Online (MEDLINE). Buscou-se por artigos em português, inglês e espanhol publicados entre o período de 2010 a 2020, considerando os descritores: "agentes antimicrobianos", "ação antimicrobiana" e “odontologia” de acordo com Pereira et al., 2018.

\section{Resultados e Discussão}

\subsection{Infecções de etiologia bacteriana}

O conhecimento do mecanismo de ação dos fármacos, a dosagem terapêutica e os possíveis efeitos adversos são de suma importância na atividade clínica odontológica, uma vez que as desordens de etiologia bacteriológica, viral e fúngica são comuns na cavidade oral e, portanto, cabe ao cirurgião-dentista conhecer qual mecanismo farmacológico aplicar em cada situação.

Os antibióticos são caracterizados por serem antimicrobianos usados para o tratamento e prevenção de infecções. Eles são classificados como bactericidas ou bacteriostáticos. Os antibióticos bactericidas matam as bactérias ao inibir a síntese da parede celular, enquanto os bacteriostáticos inibem as bactérias crescimento e reproduções (Holmes et al., 2016).

Contudo, torna-se imperativo o conhecimento prévio da sensibilidade bacteriana que o profissional visa tratar. Esse conhecimento se dá através do antibiograma. A leitura interpretada do antibiograma é baseada principalmente em dados microbiológicos e farmacodinâmicos. As informações microbiológicas separam as cepas bacterianas daquelas que não têm mecanismos de resistência aos antibióticos e aqueles que o fazem. Com esta informação e ao tratar parâmetros farmacocinéticos de cada antimicrobiano, é possível fazer aproximações farmacodinâmicas. Testes que podem prever o sucesso ou fracasso do antibiótico em uma determinada infecção (Soriano-García, 2010).

Essa prescrição tem sofrido um aumento expressivo nos últimos anos, como aponta Lucchette et al., 2019 que afirma no seu estudo um aumento de $62,2 \%$ na taxa de prescrição voltada para pacientes com 60 anos ou mais.

Como afirma também Spivak et al., 2019, no seu estudo constatou-se que os cirurgiões-dentistas prescrevem apenas $10 \%$ dos antibióticos ambulatoriais e frequentemente estão entre os 5 primeiros prescritores desses mesmos antimicrobianos.

\subsubsection{Principais grupos de antibióticos utilizados na clínica odontológica}

\section{Penicilinas}

Considerados antibióticos B-lactâmicos, essa classe atua na parede celular no momento da formação da cápsula bacteriana, ou seja, durante a fase de crescimento da célula. Portanto, o efeito produzido é bactericida. Além disso, sendo a mais utilizada no meio odontológico, a Amoxicilina 500mg ou $875 \mathrm{mg}$ é tida como padrão ouro, por agir em rápida absorção e manter-se nos níveis sanguíneos de forma mais prolongada. Geralmente, ela é administrada, por via oral, de 8 em 8 ou 12 em 
12 horas. Ela é um fármaco de primeira escolha, pelo fato de ser bactericida, de possuir eficácia contra os prováveis microrganismos presentes em infecções odontogênicas e ser uma droga de baixa toxicidade. Porém, diversas reações de hipersensibilidade estão associadas com o uso das penicilinas, manifestações como erupções cutâneas, desde as formas maculopapulosas até dermatite esfoliativa, urticária; tornando necessária à sua substituição por outro grupo de fármacos (Andrade et al., 2014).

\section{Tetraciclinas}

Esse grupo de drogas são consideradas bacteriostáticas, atuam ligando-se ao RNA de células e são usadas principalmente para tratar infecções causadas por Rickettsia, Chlamydia e Mycoplasma e várias bactérias Gram-negativas e Gram-positivas suscetíveis. Por serem bem absorvidas por via oral, a doxiciclina e a minociclina são as principais para o uso odontológico. (Brigantini et al., 2016). De acordo com Carneiro et al., 2019, os efeitos colaterais da tetraciclina podem incluir náusea, vômito, diarreia, candidíase oral, infecção vaginal, coceira anal, língua escura, colite pseudomembranosa acompanhada de diarreia, dor abdominal, pele sensível ao sol e, principalmente, alterações na pigmentação que formada no desenvolvimento dos dentes e ossos.

\section{Cefalosporinas}

Outro grupo de antibióticos betalactâmicos. São agentes bactericidas, com o mesmo mecanismo de ação das penicilinas, tendo um espectro de ação um pouco mais aumentado contra bacilos gram negativos e principalmente para estafilococos (resistentes às penicilinas). Quando utilizados por muito tempo e em altas doses, as cefalosporinas podem ter uma nefrotoxicidade maior, então deve-se ter cuidado com pacientes que fazem hemodiálise ou transplantado renal. Pacientes alérgicos às penicilinas devem ter cautela ao usar a cefalosporina, pois aproximadamente $20 \%$ dos pacientes têm reação cruzada (Brigantini et al., 2016).

Dentre os mais usados, destaca-se a cefalexina (primeira geração) e sua dosagem recomendada é de comprimido contendo 500mg de 06 em 06 horas ou suspensão $250 \mathrm{mg} / 5 \mathrm{ml}$ ou $500 \mathrm{mg} / 5 \mathrm{ml}$ (Brigantini et al., 2016).

\section{Lincosamidas}

Desde 1968, entende-se que a clindamicina tem atividade antibacteriana superior à lincomicina, bem como melhor biodisponibilidade oral. Desde então, clindamicina é, na prática, a lincosamida de referência, citada em todas as recomendações (Stahl, 2017).

Clindamicina é o antibiótico de primeira escolha para os pacientes alérgicos às penicilinas. É muito bem absorvida por via oral e possui como característica a capacidade de atravessar facilmente barreiras teciduais, bem como penetrar no interior de macrófagos e leucócitos (logo, consegue penetrar bem no pus). Sua biotransformação ocorre no fígado, sendo necessário ter cautela em pacientes com disfunções hepáticas, e excretada na bile (boa para pacientes nefropatas). É comum pacientes se queixarem de desconforto intestinal com o uso da clindamicina. $\mathrm{O}$ espectro de ação inclui o das penicilinas, estafilococos aureus, bactérias produtoras de penicilinases, bacilos anaeróbios gram-negativos. A literatura aponta sua dose usual de 150mg ou 300mg de 06 em 06 horas por via oral (Stahl, 2017).

\section{Macrolídeos}

Este grupo tem uma ampla gama de utilizações na odontologia, embora não seja a primeira droga de escolha, mas é boa escolha para quem sofre de alergias à penicilina. São drogas antibacterianas que inibem a função dos ribossomos, permitindo que o sistema de defesa do hospedeiro elimine a infecção. Dentre os macrolídeos, a azitromicina é a mais usada e 
tem um maior espectro antibacteriano contra Streptococcus e Staphylococcus, sendo administrada em dose única de $500 \mathrm{mg}$ por 3 dias, podendo ser estendida até 5 dias (Andrade et al., 2014).

\section{Nitroimidazólicos}

Dentre os nitroimidazólicos, o metronidazol é o mais usado pela classe odontológica, para a microbiota anaeróbica e inclui especialmente essas espécies. No entanto, visto que as infecções orais dificilmente são causadas apenas por essas espécies, esta medicação é associada a outros antibióticos. Geralmente, é administrado na dose de $500 \mathrm{mg}, 3$ a 4 vezes ao dia. Seu mecanismo bactericida, sua alta perfusão tecidual e sua alta concentração no fluido crevicular e na saliva tornam este medicamento um bom remédio adjuvante para infecções anaeróbicas. Um efeito colateral comum desse antibiótico é a diminuição de bactérias na cavidade oral, com infecção repetida causada por outras infecções organismos, o mais comum é Candida albicans (Andrade et al., 2014).

\subsection{Infecções de origem fúngicas}

A microbiota oral dos indivíduos saudáveis é composta por uma variedade de microrganismos, incluindo os fungos. Com isso, as condições existentes no ambiente oral e em todo o organismo são fatores imprescindíveis para a manutenção do equilíbrio fisiológico concomitantemente da presença desses microbianos. Portanto, é evidente que o desenvolvimento das doenças fúngicas resulta dos fatores de virulência dos fungos e dos fatores predisponentes do hospedeiro (Quindós et al., 2019).

Dentre as condições favoráveis no indivíduo para a patogenia, estão: presença de fluxo salivar reduzido, deficiência nutricional, diabetes, imunodeficiência, utilização de antibióticos e esteróides, uso de aparelho intra-oral e tabagismo (Lewis e Williams, 2017).

Tomando como base a candidíase oral, infecção fúngica bastante recorrente, e sendo o principal fungo causador a levedura Candida albicans, sabe-se que tal microbiano, em um ambiente favorável, tem a capacidade de aderir às superfícies do epitélio oral e de dispositivos protéticos. É de conhecimento científico que, após essa adesão, o fungo pode mudar a sua estrutura para filamentos causando danos ao hospedeiro, além da liberação extracelular de enzimas (proteases e fosfolipases) (Brandão et al., 2021).

A identificação das causas predisponentes com posterior eliminação geralmente promove uma regressão da infecção e o retorno à homeostasia da microbiota oral. Contudo, a terapia antifúngica é um importante auxílio. Por isso, a identificação do fungo é indispensável para a orientação do tratamento das lesões (Neville et al., 2016).

Os antifúngicos possuem diferentes mecanismos de ação para conter a infecção, os poliênicos (nistatina, anfotericina B), por exemplo, atuam formando poros aquosos na célula fúngica provocando, assim, o extravasamento dos seus componentes. Já o fluconazol e o itraconazol interferem na síntese de ergosterol, um componente importante na estruturação e no funcionamento da membrana (Lewis e Williams, 2017).

Considerando-se a aplicação desses medicamentos, os poliênicos foram os primeiros antifúngicos descobertos e, por muito tempo, o único meio medicamentoso existente para as micoses. Todavia, estão limitados a uma aplicação tópica, pois há uma má absorção desses fármacos pelo intestino. Ademais, a anfotericina B pode provocar sistemicamente efeitos colaterais e uma toxicidade relevante (Brandão et al., 2021).

A terapêutica preferencial para a candidíase oral, a depender da lesão, é a tópica. A partir disso, a nistatina é um antifúngico bastante utilizado principalmente na forma de suspensão e, dentre as suas vantagens, pode ser administrado durante a gravidez. A posologia fica entre $1 \mathrm{ml} \mathrm{a} 6 \mathrm{ml}, 4$ vezes ao dia, durante 15 a 21 dias. O miconazol é um imidazólico também muito utilizado topicamente (Lewis e Williams, 2017). 
Os antifúngicos sistêmicos são indicados como auxiliares, se necessário, da medicação tópica ou quando a terapia tópica não foi eficaz para regredir a infecção e tratar as lesões.

Os antifúngicos azólicos são muito utilizados no tratamento de diversas micoses por causa da variedade nas formas de administração e da baixa incidência de efeitos colaterais. $\mathrm{O}$ fluconazol pode ser administrado oralmente em forma de cápsula e de suspensão ou pela via intravenosa. Na candidíase pseudomembranosa (sapinho) e na eritematosa aguda, pode ser recomendada a terapia com o uso do fluconazol $50 \mathrm{mg}$, uma vez por dia durante sete dias (Lewis e Williams, 2017). Quando a doença resiste ao fluconazol, recomenda-se o itraconazol em solução $200 \mathrm{mg}$ uma vez ao dia por, no máximo, quatro semanas (Quindós et al., 2019).

Outra forma de candidíase na qual o tratamento é feito com azólicos, é a eritematosa crônica. Uma vez que essa candidíase é bastante associada ao uso de prótese dentária, pois ocorre o surgimento de vermelhidão na mucosa em contato com a mesma, logo, o fungo a coloniza. Portanto, o tratamento consiste na sua desinfecção. Para isso, uma das terapêuticas recomendadas é o uso do miconazol aplicado de forma tópica na superfície de encaixe (Lewis e Williams, 2017).

É importante ressaltar que os fármacos azólicos apresentam interação medicamentosa com a varfarina e as estatinas, sendo contraindicado o uso concomitante desses medicamentos. Além disso, também é contraindicada a prescrição para grávidas e lactantes.

As equinocandinas (anidulafungina, caspofungina) são antifúngicos intravenosos que podem ser utilizados prioritariamente no tratamento de candidíase oral grave, incluindo em pacientes imunodeficientes, devido a sua ação prolongada e de anti-biofilme. Esses medicamentos não devem ser receitados durante a gravidez e a amamentação (Quindós $e t$ al., 2019).

\section{Conclusão}

O manejo adequado das substâncias farmacológicas é condição obrigatória para um bom prognóstico da patologia previamente diagnosticada. Faz-se necessário, então, que o profissional prescritor esteja atento a todas as peculiaridades inerentes ao fármaco que está prescrevendo a fim de buscar a correta resolubilidade do problema.

Devido ao vasto arcabouço medicamentoso disponível no mercado, o uso incorreto destes poderá gerar consequências que venham intervir na boa evolução clínica desses pacientes.

\section{Referências}

Andrade, E. D. (2014). Terapêutica medicamentosa em odontologia. Artes Médicas Editora.

Amato Neto, V., Lopes, H. V., Baldy, J. L. D. S., Levi, G. C., \& Mendonça, J. S. D. (2000). Antibióticos na prática médica. In Antibióticos na prática médica (304-304).

Brandão, H. N., Meira, I. A., Dalle Piagge, C. S. L., \& Cosme-Trindade, D. C. (2021). Fitoterapia no tratamento da candidíase oral: Um protocolo de revisão de escopo. Research, Society and Development, 10(7), e35010716653-e35010716653.

Brigantini, L. C. et al. (2016). Antibióticos em Odontologia. Revista Uningá, Paraná,. 49(1), 121-7.

Carneiro, M. D. A. (2019). Conhecimento dos alunos de odontologia sobre antibióticos: Construção de um questionário.

Cintra, J. N. (2015). Risco de endocardite bacteriana no tratamento endodôntico: Revisão de literatura. Investigação, Universidade de Franca, v. 14, n. 1, p. $169-174$,

Clercq, E., \& Guangdi, L. I., (2016). Approved antiviral drugs over the past 50 years. Clinical microbiology reviews. 29(3), 695-747.

Fuchs, F. D., et al. (2017). Farmacologia Clínica e Terapêutica. (5. ed.) Guanabara Koogan, 863 p.

Gonçalves, L. C. (2020). Prevalência de genes de resistência a antibióticos em infeções periodontais: $\beta$-lactâmicos (Doctoral dissertation).

Holmes, C. J., \& Pellecchia ,A. R. (2016). Antimicrobial Therapy in Management of Odontogenic Infections in General Dentistry. Dental Clinics of North America, Estados Unidos, 60(2), 497-507. 
Research, Society and Development, v. 10, n. 14, e95101421668, 2021

(CC BY 4.0) | ISSN 2525-3409 | DOI: http://dx.doi.org/10.33448/rsd-v10i14.21668

Lewis, M. \& Williams, D.W. (2017). Diagnosis and management of oral candidosis. British Dental Journal, Reino Unido, 223(9), 675-679.

Lira, C. C., Morais, E. S. D., Ely, M. R., Thomas, É. B. A. F., Batista, O. D. M., \& Sampaio, M. C. C. (2001). Indicações da utilização de antibióticos nas infecções buco-dentárias primárias e suas complicações secundárias. Rev. fac. odontol. Univ. Fed. Bahia, 60-65.

Lucchette, A. C. T., Tenani, C. F., de Fátima Possobon, R., \& Batista, M. J. (2019). Avaliação da prática de prescrição de antibióticos pelos cirurgiõesdentistas da Rede Pública de um município de médio porte. Arquivos em Odontologia, 55.

Millsop, J. W., \& Fazel, N. (2016). Oral candidiasis. Clinics in dermatology, 34(4), 487-494.

Neville, B. W. et al., (2016). Patologia oral e maxilofacial. (4. ed.) Elsevier, p.465-477.

Pereira A. S. et al. (2018). Metodologia da pesquisa científica. [free e-book]. Santa Maria/RS. Ed. UAB/NTE/UFSM.

Quindós, G., Gil-Alonso, S., Marcos-Arias, C., Sevillano, E., Mateo, E., Jauregizar, N., \& Eraso, E. (2019). Ferramentas terapêuticas para candidíase oral: Antifúngicos atuais e novos. Medicina oral, patologia oral y cirugia bucal , 24 (2), e172.

Samaranayake, L. (2012). Fundamentos de microbiologia e imunologia na odontologia. Elsevier Brasil.

Soriano-García, F. (2010). Aspectos farmacocinéticos y farmacodinámicos para la lectura interpretada del antibiograma. Enfermedades infecciosas y Microbiología Clínica, 28(7), 461-466.

Spivak, E. S. (2019). Antibiotic Use in Dentistry: What We Know and Do Not Know. JAMA network open, Estados Unidos, 2(5), 1-5.

Stahl, J. P. (2017). Lincosamidas. EMC-Tratado de Medicina, 21(4), 1-4. 